\title{
Effects of mutual intercropping of tomato on soil enzyme activity and available selenium under selenium stress
}

\author{
Minghong $\mathrm{Yu}^{1}$, Yuefeng Hou ${ }^{1}$, Yuhui $\mathrm{Bie}^{1}$, Xu Chen ${ }^{1}$, Yiping Dong ${ }^{1}$ and Yi Tang ${ }^{2 *}$ \\ ${ }^{1}$ College of Horticulture, Sichuan Agricultural University, Chengdu, Sichuan, 611130, China \\ ${ }^{2}$ Institute of Pomology and Olericulture, Sichuan Agricultural University, Chengdu, Sichuan, 611130, China
}

\begin{abstract}
In order to study the effect of mutual intercropping tomato on soil enzyme activity and available selenium content in selenium-containing soil, cherry tomatoes of red, yellow and purple varieties were selected for pairwise and three intercrops in this experiment respectively. The results showed that the activities of sucrase, phosphatase and urease in soil were increased after the three kinds of tomato were intercropped with each other, and the highest soil enzyme activity was found when red and purple tomatoes were mixed. Soil $\mathrm{pH}$ reached the maximum when three tomatoes were mixed. The content of available selenium in soil after intercropping tomato was higher than monoculture, and the content of available selenium was the highest when red and yellow tomatoes were mixed. Therefore, intercropping could improve the soil microecological environment, increase soil enzyme activity and increase available selenium content in tomato rhizosphere soil.
\end{abstract}

\section{Introduction}

Soil enzymes are mainly derived from soil microorganisms and plant root exudates. Soil enzymes can accelerate the metabolism of soil and promote the cycling of nutrient elements [1]. It is of great significance to improve soil fertility by increasing soil enzyme activity. Selenium (Se) is an essential trace element of animals and human beings, and it is an important part of selenoprotein. It has the functions of scavenging free radicals, delaying senility, improving immunity and preventing cancer, etc $[2,3]$. Se deficiency in food is a worldwide problem. The low bioavailability of Se in soil leads to the low content of Se in food [4]. Soil available Se can be effectively utilized by ecosystem and is closely related to human health. It is an important index to evaluate the ecological effect of selenium.

Intercropping can improve the utilization of light, temperature, water, fertilizer and other resources by utilizing the principle of biodiversity. Intercropping always has been an important agroforestry technology, which has been widely used in the world [5]. Some studies have shown that intercropping garlic and cucumber can increase soil enzyme activity, soil microbial environment, effectively alleviate the harm of soil diseases, and thus promote the growth of cucumber plants [6]. Intercropping tomato and leguminous plants can significantly increase the soil urease, invertase and phosphatase activities and the yield of tomato [7]. However, there are few reports on the effects of intercropping tomato on soil enzyme activity and available Se content.
Cherry tomato (Lycopersivon esculentum), also known as pearl fruit and small tomato, is one of the four major fruits listed as priority by the Food and Agriculture Organization of the United Nations [8]. In this experiment, the effects of mutual intercropping different genotypes of cherry tomato on soil enzyme activity and available Se were studied under the condition of applying exogenous Se. It provides a reference for establishing an excellent cultivation model and improving Se content in cherry tomato.

\section{Materials and methods}

\subsection{Materials}

Three kinds of cherry tomato, red (Y20-1), yellow (4-1) and purple (13-1), were used as materials, all of which belonged to Institute of Pomology and Olericulture, Sichuan Agricultural University belonging to multiple generations of inbred line with stable homozygous characters. The sodium selenite was purchased from Kelong Chemical Reagent Factory. The soil was paddy soil, which were taken from farmland around Chengdu Campus of Sichuan Agricultural University and no Se was detected.

\subsection{Experimental design}

Dry the damp soil from the nearby farmland of Chengdu Campus of Sichuan Agricultural University, then pass through $5 \mathrm{~mm}$ sieve and put into $34 \mathrm{~cm} \times 40 \mathrm{~cm}$ (high $\times$ diameter) pot, $20 \mathrm{~kg}$ per bucket. $\mathrm{Na}_{2} \mathrm{O}_{3} \mathrm{Se} \cdot 5 \mathrm{H}_{2} \mathrm{O}$

\footnotetext{
*Corresponding author's e-mail: 95459425@qq.com
} 
analytical pure solution was added to the soil to make Se concentration $10 \mathrm{mg} / \mathrm{kg}$. Soil was kept moist, placed for 4 weeks, mixed all the soil thoroughly, weighted $16 \mathrm{~kg}$ and put them in a $34 \mathrm{~cm} \times 40 \mathrm{~cm}$ (high $\times$ diameter) pot.

The uniform size of cherry tomato seeds was sterilized in $10 \% \mathrm{H}_{2} \mathrm{O}_{2}(\mathrm{~m} / \mathrm{m})$ for $10 \mathrm{~min}$, and then rinsed with ultrapure water. The sterilized seeds were placed evenly in culture dishes and germinated in an artificial incubator at $25{ }^{\circ} \mathrm{C}$. After the seeds were exposed, they were planted in a pit tray ( 32 holes) with special substrate for vegetable cultivation. For each of the three genotypes of cherry tomatoes have four plates.

When tomato seedlings grew to 4-5 true leaves, selected the same size and strong seedlings and transferred them to the prepared pot. There were 6 plants in each pot for monoculture of red (TR), yellow (TY), purple (TP), 3 plants in each variety for interplanting of red and yellow (TRY), red and purple (TRP), yellow and purple (TYP), and 2 plants in each variety for interplanting of red, yellow and purple (TRYP), each treatment was replicated 10 times. Completely random discharge, exchanged the pot positions irregularly to reduce marginal effects, and regularly remove weeds to prevent pests and diseases.

\subsection{Determination of Soil Enzyme Activity, pH and Available Selenium Content}

After the cherry tomatoes entered the fruiting stage, the $\mathrm{pH}$ of rhizosphere soil was measured. Then the "rhizosphere soil" samples were collected. After air-dried and pass through $1 \mathrm{~mm}$ sieve, the samples were preserved for determining the soil enzyme activity and available Se content. The $\mathrm{pH}$ value was determined by $\mathrm{pH}$ meter and soil enzyme activity was referred to "Soil Enzyme and Iits Research Method" [9]. The activity of urease was determined by indigo-phenol colorimetry, catalase activity was determined by Potassium Permanganate titration, phosphatase activity was determined by p-Nitrobenzene phosphate method and the activity of sucrase was determined by titration. Soil samples were mixed with extractants (potassium dihydrogen phosphate of $0.1 \mathrm{~mol} / \mathrm{L}$ ) in a ratio of $1: 5$ and shaken in a shaking table for two hours before filtration. Then the available Se content in soil was determined by atomic absorption spectrophotometer (Aaanlust800).

\subsection{Statistical Analyses}

All data were processed with Excel 2010 software and analysed by means of one-way ANOVA in combination with the least significant difference (LSD) test using SPSS 20.0 statistical software (IBM Corporation, Armonk, NY, USA). Significance was assessed at the 5\% level of probability.

\section{Results}

\subsection{Effect of Intercropping Tomato on Soil Enzyme Activity}

The results showed that soil sucrase, phosphatase and urease activities of intercropping increased compared with monoculture under selenium treatment, the soil enzyme activity was the highest in TRP, and the lowest in TY (Table 1). Among them, the soil sucrase activity of TRP was $29.21 \%(P<0.05)$ and $44.16 \%(P<0.05)$ higher than the than the treatments with TR and TP, and the maximum value was $3.45 \mathrm{mg} / \mathrm{g} / \mathrm{d}$, the lowest value was $2.25 \mathrm{mg} / \mathrm{g} / \mathrm{d}$; The soil phosphatase activity of TRP was $22.84 \%(P<0.05)$ and $17.25 \%(P<0.05)$ higher than the treatments with TR and TP, and the maximum value was $60.57 \mathrm{mg} / 100 \mathrm{~g} / 2 \mathrm{~h}$, the lowest value was 44.83 $\mathrm{mg} / 100 \mathrm{~g} / 2 \mathrm{~h}$; The urease activity of TRP was $36.32 \%(P$ $<0.05)$ and $9.60 \%(P<0.05)$ higher than the treatments with TR and TP, and the maximum value was $2.74 \mathrm{mg} / \mathrm{g} / \mathrm{d}$, the lowest value was $1.81 \mathrm{mg} / \mathrm{g} / \mathrm{d}$.

Table 1. Effects of mutual intercropping of tomato on soil enzyme activity.

\begin{tabular}{cccc}
\hline Treatment & $\begin{array}{c}\text { Sucrase activity } \\
(\mathrm{mg} / \mathrm{g} / \mathrm{d})\end{array}$ & $\begin{array}{c}\text { Phosphatase activity } \\
(\mathrm{mg} / 100 \mathrm{~g} / 2 \mathrm{~h})\end{array}$ & $\begin{array}{c}\text { Urease activity } \\
(\mathrm{mg} / \mathrm{g} / \mathrm{d})\end{array}$ \\
\hline TR & $2.67 \pm 0.17 \mathrm{c}$ & $49.31 \pm 1.36 \mathrm{c}$ & $2.01 \pm 0.01 \mathrm{c}$ \\
TY & $2.25 \pm 0.08 \mathrm{~d}$ & $44.83 \pm 2.01 \mathrm{~d}$ & $1.81 \pm 0.12 \mathrm{c}$ \\
TP & $2.38 \pm 0.07 \mathrm{~d}$ & $51.66 \pm 1.39 \mathrm{bc}$ & $2.50 \pm 0.08 \mathrm{~b}$ \\
TRY & $2.74 \pm 0.15 \mathrm{bc}$ & $52.29 \pm 1.08 \mathrm{bc}$ & $2.69 \pm 0.02 \mathrm{ab}$ \\
TRP & $3.45 \pm 0.09 \mathrm{a}$ & $60.57 \pm 1.73 \mathrm{a}$ & $2.74 \pm 0.06 \mathrm{a}$ \\
TRYP & $2.81 \pm 0.12 \mathrm{bc}$ & $58.03 \pm 1.03 \mathrm{a}$ & $2.53 \pm 0.07 \mathrm{~b}$ \\
TYP & $2.58 \pm 0.09 \mathrm{~cd}$ & $54.26 \pm 1.48 \mathrm{~b}$ & $2.59 \pm 0.05 \mathrm{~b}$ \\
\hline
\end{tabular}

Different letters within same column indicate significant differences at $P \leq 0.05$ significance level between treatments according to the Duncan's multiple range test.

\subsection{Effect of Intercropping Tomato on Soil pH and Available Selenium Contents}


Table 2. Effects of mutual intercropping of tomato on soil $\mathrm{pH}$ and available selenium content.

\begin{tabular}{ccc}
\hline Treatment & $\mathrm{pH}$ & Soil available Se $(\mu \mathrm{g} / \mathrm{kg})$ \\
\hline TR & $5.09 \pm 0.03 \mathrm{c}$ & $11.31 \pm 0.88 \mathrm{c}$ \\
TY & $5.04 \pm 0.06 \mathrm{c}$ & $12.49 \pm 0.13 \mathrm{~b}$ \\
TP & $5.22 \pm 0.04 \mathrm{bc}$ & $12.05 \pm 0.20 \mathrm{~b}$ \\
TRY & $5.33 \pm 0.03 \mathrm{ab}$ & $13.86 \pm 0.31 \mathrm{a}$ \\
TRP & $5.30 \pm 0.04 \mathrm{ab}$ & $13.48 \pm 0.28 \mathrm{a}$ \\
TRYP & $5.46 \pm 0.03 \mathrm{a}$ & $13.30 \pm 0.52 \mathrm{a}$ \\
TYP & $5.40 \pm 0.09 \mathrm{a}$ & $13.58 \pm 0.75 \mathrm{a}$ \\
\hline
\end{tabular}

Different letters within same column indicate significant differences at $P \leq 0.05$ significance level between treatments according to the Duncan's multiple range test.

The soil $\mathrm{pH}$ of intercropping was significantly higher than that of either monoculture (Table 2). The soil pH value of TRYP was $7.27 \%(P<0.05), 8.33 \%(P<0.05)$ and $4.60 \%(P<0.05)$ higher than the treatments with TR, $\mathrm{TY}$ and TP, and the maximum value was 5.46. As for the content of available Se in soil, the change varied little between treatments and the highest was TRY at 13.86 $\mu \mathrm{g} / \mathrm{kg}$, the lowest was TR at $11.31 \mu \mathrm{g} / \mathrm{kg}$. The content of available Se in soil of cherry tomato was significantly increased after intercropping with each other and the content of available Se in soil of TRY was $22.55 \%(P<$ $0.05)$ and $10.97 \%(P<0.05)$ higher than the treatments with TR and TY; The content of available Se in soil of TRP was $19.19 \%(P<0.05)$ and $11.87 \%(P<0.05)$ higher than the treatments with TR and TP; The content of available $\mathrm{Se}$ in soil of TRYP was $17.60 \%(P<0.05)$, $6.49 \%(P<0.05)$ and $10.37 \%(P<0.05)$ higher than the treatments with TR, TY and TP; The content of available Se in soil of TYP was $8.73 \%(P<0.05)$ and $12.70 \%(P$ $<0.05)$ higher than the treatments with TY and TP.

\section{Conclusion}

The soil sucrase activity, phosphatase activity, urease activity, $\mathrm{pH}$ value and soil available Se content of the three genotypes of cherry tomato were all increased by mixing with each other. In different mixed planting modes, the soil enzyme activity was the highest when red and purple cherry tomatoes were mixed in pairs, and the available Se content in soil increased with the increase of soil $\mathrm{pH}$ value.

\section{References}

1. Li, Y., Zhang, L.P., Fang, S.Z., Tian, Y., Guo, J. (2018) Variation of soil enzyme activity and microbial biomass in poplar plantations of different genotypes and stem spacings. Journal of Forestry Research, 29(4):963-972.

2. Savarino, L., Granchi, D., Ciapetti, G., Cenni, E., Ravaglia, G., Forti, P., Maioli, F., Mattioli, R. (2001) Serum concentrations of zinc and selenium in elderly people: results in healthy nonagenarians/centenarians. Experimental Gerontology, 36:327-339.
3. James, C., Fleet, Ph.D. (1997) Dietary selenium repletion may reduce cancer incidence in people at high risk who live in areas with low soil selenium. Nutrition Reviews, 55(7): 277-279.

4. Hawkesford, M. J, Zhao, F. J. (2007) Strategies for increasing the selenium content of wheat. Journal of Cereal Science, 46(3):282-292.

5. Ma, Y.H., Fu, S.L., Zhang, X.P., Zhao, K., Chen, H.Y.H. (2017) Intercropping improves soil nutrient availability, soil enzyme activity and tea quantity and quality. Applied Soil Ecology, 119: 171-178.

6. Du, L.T., Huang, B.J., Du, N.S., Guo, S.R., Shu, S., Sun, J. (2017) Effects of Garlic/Cucumber Relay Intercropping on Soil Enzyme Activities and the Microbial Environment in Continuous Cropping. HortScience, 52(1):78-84.

7. Dai, H.H., Hu, X.F., Cao, M.Y., Yang, M.Y., Wang, J. (2015) Effects of intercropping with leguminous crops on tomato yield, soil nutrients and enzyme activity. Acta Pedologica Sinica, 52(4): 911-918.

8. Tian, J., Ban, X.Q., Zeng, H., Huang, J.S., Wang, Y.W. (2011) In vitro and in vivo activity of essential oil from dill (Anethum graveolens L.) against fungal spoilage of cherry tomatoes. Food Control, 22(12):1992-1999.

9. Guan, S.Y. (1986) Soil enzyme and its research methods. Agricultural Press, Beijing.

10. Li, H.Y., Jin, M., Liu, C.M., Li, Z.G., Xiong, Y.F., Ge, D.Z. (2005) Fluorescence determination of selenium in soil. Journal of Hunan Agricultural University (Natural Science Edition), 31(4): 370-372. 